\title{
Overexpression of SDF-1 activates the NF-кB pathway to induce epithelial to mesenchymal transition and cancer stem cell-like phenotypes of breast cancer cells
}

\author{
LINGXIN KONG $^{1}$, SUFEN GUO $^{2}$, CHUNFENG LIU $^{1}$, YILING ZHAO ${ }^{1}$, \\ $\mathrm{CHONG} \mathrm{FENG}^{1}$, YUNSHUANG LIU ${ }^{1}$, TAO WANG ${ }^{1}$ and CAIJUAN LI ${ }^{1}$ \\ ${ }^{1}$ Department of Medical Ultrasonics, Hongqi Hospital of Mudanjiang Medical University; \\ ${ }^{2}$ Key Laboratory of Cancer Prevention and Treatment of Heilongjiang Province, \\ Mudanjiang Medical University, Mudanjiang, Heilongjiang 157011, P.R. China
}

Received August 20, 2015; Accepted December 2, 2015

DOI: $10.3892 /$ ijo.2016.3343

\begin{abstract}
The formation of EMT and EMT-induced CSC-like phenotype is crucial for the metastasis of tumor cells. The stromal cell-derived factor-1 (SDF-1) is upregulated in various human carcinomas, which is closely associated with proliferation, migration, invasion and prognosis of malignancies. However, limited attention has been directed towards the effect of SDF-1 on epithelial to mesenchymal transition (EMT) or cancer stem cell (CSC)-like phenotype formation in breast cancer cells and the related mechanism. In the present study, we screened MCF-7 cells with low SDF-1 expression level for the purpose of evaluating whether SDF-1 is involved in EMT and CSC-like phenotype formation in MCF-7 cells. The pEGFP-N1-SDF-1 plasmid was transfected into MCF-7 cells, and the stably overexpressed SDF-1 in MCF-7 cells was confirmed by real-time PCR and western blot analysis. Colony formation assay, MTT, wound healing assay and Transwell invasion assay demonstrated that overexpression of SDF-1 significantly boosted the proliferation, migration and invasion of MCF-7 cells compared with parental $(\mathrm{P}<0.05)$. Flow cytometry analysis revealed a notable increase of $\mathrm{CD}_{4} 4^{+} /$ CD24- subpopulation in SDF-1 overexpressing MCF-7 cells $(\mathrm{P}<0.001)$, accompanied by the apparently elevated ALDH activity and the upregulation of the stem cell markers OCT-4, Nanog, and SOX2 compared with parental $(\mathrm{P}<0.01)$.
\end{abstract}

Correspondence to: Dr Caijuan Li, Department of Medical Ultrasonics, Hongqi Hospital of Mudanjiang Medical University, 5 Tongxiang Road, Mudanjiang, Heilongjiang 157011, P.R. China E-mail: caijuanli123@163.com

Abbreviations: SDF-1, stromal cell-derived factor-1; EMT, epithelial to mesenchymal transition; CSC, cancer stem cell

Key words: stromal cell-derived factor-1, MCF-7 cells, breast cancer, epithelial to mesenchymal transition, cancer stem cell-like phenotypes
Besides, western blot analysis and immunofluorescence assay observed the significant decreased expression of E-cadherin and enhanced expression of slug, fibronectin and vimentin in SDF-1 overexpressed MCF-7 cells in comparison with parental $(\mathrm{P}<0.01)$. Further study found that overexpression of SDF-1 induced the activation of NF- $\kappa \mathrm{B}$ pathway in MCF-7 cells. Conversely, suppressing or silencing p65 expression by antagonist or RNA interference could remarkably increase the expression of E-cadherin in SDF-1 overexpressed MCF-7 cells $(\mathrm{P}<0.001)$. Overall, the above results indicated that overexpression of SDF-1 enhanced EMT by activating the NF- $\kappa \mathrm{B}$ pathway of MCF-7 cells and further induced the formation of CSC-like phenotypes, ultimately promoting the proliferation and metastasis of MCF-7 cells. Therefore, SDF-1 may further be assessed as a potential target for gene therapy of breast cancer.

\section{Introduction}

Breast cancer is one of the most common malignancies in women, with $\sim 1.05$ million new cases annually and $3.1 \%$ increasing rate $(1,2)$. Currently, surgery, chemotherapy, radiotherapy and endocrine therapy are the mainstream clinical strategies for breast cancer, but $25 \%$ mortality rate still remains (3). The deterioration and poor prognosis of breast cancer are attributed to tumor invasion and metastasis (1). Epithelialmesenchymal transition (EMT) and EMT-induced acquisition of cancer stem cell (CSC)-like phenotypes are crucial for invasion and metastasis of tumor cells (4-7). Hence, finding the key molecules that regulate formation of EMT and CSCs is warranted to reveal the pathological progression of breast cancer and develop novel therapeutic approaches.

The stromal cell-derived factor-1 (SDF-1, CXCL12) is a highly conserved chemoattractant cytokine responsible for regulating diverse biological processes ranging from embryonic development, stem cell movement, angiogenesis and tumor generation (8-10). Clinical research reported that the expression of SDF-1 was elevated significantly in various carcinomas associated with tumor grade, lymph node metastasis, TNM stage and prognosis (11-13). Moreover, the organs 
with constitutive SDF-1 secretion, such as liver, lung, lymph nodes, and bone marrow, are also the most common sites for secondary metastasis of breast cancer (14-16). On the contrary, as a potent leukocytic chemokines, CXCL12 also has a potential to promote anticancer immunity by inducing $\mathrm{CD}^{+} \mathrm{T}$ cell activity, enhancing cytotoxicity, increasing the number of CD11 $\mathrm{c}^{+}$cells in the tumor-draining lymph nodes and reducing the accumulation of myeloid-derived suppressor cells in the spleen (17). In vitro studies revealed that SDF-1 was secreted by cancer associated fibroblasts (CAFs) or myofibroblasts and bound to its receptors (CXCR4 and CXCR7) on cancer cell surface to activate downstream intracellular signal pathways that regulate the metastasis, angiogenesis, and drug-resistant of cancer cells (18). Gao et al and Jiang et al both demonstrated that the proliferation, migration and invasion of pancreatic cancer cells and epithelial ovarian cancer cells were enhanced through SDF-1/CXCR4 axis after treating with certain concentrations of SDF-1 $(19,20)$. Kang et al overexpressed SDF-1 in MDA-MB-231 cells to create an autocrine loop of SDF-1/CXCR4 and found that SDF-1 boosted the invasiveness and migration of breast cancer cells (21). Although SDF-1 is crucial for the migration and invasion of cancer cells, little is known about the roles of SDF-1 in EMT or CSC-like phenotype formation in breast cancer and the detailed mechanisms.

In the present study, we established SDF-1 overexpressing MCF-7 cells to investigate the effect of SDF-1 on the proliferation, migration, invasion, EMT, and CSC-like phenotype formation in breast cancer cells and explore the underlying mechanism. The results showed that overexpression of SDF-1 induced EMT of MCF-7 cells through the NF- $\kappa$ B pathway to obtain the CSC-like phenotypes, ultimately facilitating metastasis of breast cancer cells.

\section{Materials and methods}

Cell lines and mammosphere culture. MDA-MB-231, MDA-MB-435, and MCF-7 cell lines were purchased from Shanghai Institutes for Biological Sciences, Chinese Academy of Sciences. All cells were cultured in Dulbecco's modified Eagle's medium (DMEM, Gibco, Grand Island, NY, USA) containing $10 \%$ fetal bovine serum (FBS, Hyclone, Logan, $\mathrm{UT}, \mathrm{USA})$ and streptomycin/penicillin $(100 \mathrm{U} / \mathrm{ml})$ at $37^{\circ} \mathrm{C}$ in a $5 \% \mathrm{CO}_{2}$ incubator. When cells reached $80-90 \%$ confluence, western blot analysis was employed to select a cell line with the lowest SDF-1 expression for subsequent experiments.

MCF-7 cell mammospheres were cultured according to previously published methods by Wang et al (22). Briefly, MCF-7 cells were suspended in serum-free DMEM/F12 (1:1) medium containing $20 \mathrm{ng} / \mathrm{ml}$ epidermal growth factor (EGF, PeproTech, St. Louis, MO, USA), $10 \mathrm{ng} / \mathrm{ml}$ basic fibroblast growth factor (b-FGF, PeproTech), B27 (Gibco), and ITS (insulin, transferrin and selenium, Sigma-Aldrich, St. Louis, MO, USA), and seeded into ultralow attachment plates (Corning, NY, USA) at a density of $1 \times 10^{5}$ cells $/ \mathrm{ml}$. Fresh mammosphere media $(2 \mathrm{ml})$ was added into the well every 2-3 days without removing the old media. Mammospheres were collected every seven days for subsequent experiment.

Conduction of SDF-1 overexpressing vector and transfection. Full length SDF-1 coding sequences were amplified by PCR, and cloned into the EcoRI-BamHI fragment of pEGFP-N1 expression vector. The primers of SDF-1 were designed as follows: forward, 5'-TCAGAATTCATGAACGCCAAGGT CGTGG-3' (the underline represents EcoRI site); reverse, 5'-CCTCGGATCCTCACATCTTGAACCTC-TTG-3' (the underline represents BamHI site). Subsequently, the plasmid pEGFP-N1-SDF-1 was transfected into MCF-7 cells using Lipofectamine 2000 reagent (Invitrogen, Carlsbad, CA, USA) strictly following the manufacturer's instructions. The nontransfected control cells and the cells with the empty vector transfected (pEGFP-N1) were evaluated in parallel as control. The stably transfected cells were screened by G418 (400 $\mu \mathrm{g} /$ $\mathrm{ml}$, Invitrogen) after $24 \mathrm{~h}$ of transfection. As pEGFP-N1 plasmid contains green fluorescent protein, we employed a fluorescence microscope to investigate and calculate the efficiency after $24 \mathrm{~h}$ of transfection which was $25-35 \%$. Then the expression of SDF-1 was examined at 7-14 days of transfection.

Real-time (RT)-PCR. Total RNA from MCF-7 cells was extracted by High Purity Total RNA Fast Extraction kit (BioTeke, Beijing, China) following the manufacturer instructions and then reverse-transcribed into cDNA. RT-PCR was carried out by Exicycler ${ }^{\mathrm{TM}} 96$ (Bioneer, Daejeon, Korea) using SYBR Green mastermix (Solarbio, Beijing, China) with the following protocol: initial denaturation at $95^{\circ} \mathrm{C}$ for $10 \mathrm{~min}, 40$ cycles consisting of $95^{\circ} \mathrm{C}$ for $10 \mathrm{sec}, 60^{\circ} \mathrm{C}$ for $20 \mathrm{sec}$ and $72^{\circ} \mathrm{C}$ for $30 \mathrm{sec}$. Primer sequences were: OCT4, 5'-AGCGATCAAG CAGCGACTA-3' (forward) and 5'-GGAAAGGGACCGAGG AGTA-3' (reverse); Nanog, 5'-GCAGGCAACTCACTTTA TCC-3' (forward) and 5'-CCCACAAATCACAGGCATAG-3' (reverse); SDF-1, 5'-GTGCCCTTCAGATTGTAGCC-3' (forward) and 5'-CCTTCCCTAACACTGGTTTCA-3' (reverse); SOX2, 5'-CATCACCCACAGCAAATGAC-3' (forward) and 5'-CAAAGCTCCTACCGTACCACT-3' (reverser); $\beta$-actin, 5'-CTTAGTTGCGTTACACCCTTTC TTG-3' (forward) and 5'-CTGTCACCTTCACCGTTCCAG TTT-3' (reverse). Relative expression was obtained by $2^{-\Delta \Delta C T}$ method. $\beta$-actin served as an internal control.

Colony formation assay. Cells were resuspended in DMEM complete media and seeded in $35-\mathrm{mm}$ plates at a density of $10^{2}$ cells/ plate. All plates were incubated at $37^{\circ} \mathrm{C}$ in an atmosphere of $5 \% \mathrm{CO}_{2}$ for $\sim 14$ days. The suspension was decanted and replaced with fresh medium every 3 days. Then cells were fixed in $4 \%$ formaldehyde for $20 \mathrm{~min}$. After being washed twice with phosphate-buffered salines (PBS, pH 7.4), cells were stained with Wright-Giemsa dye composite for $5 \mathrm{~min}$. The number of colonies was calculated with an inverted microscope. Cells containing $>50$ cells were counted as a colony.

MTT analysis. Cells were plated in 96-well plates at a density of $2 \times 10^{3}$ per well with five replicates for each testing point and cultured in a $37^{\circ} \mathrm{C}, 5 \% \mathrm{CO}_{2}$ incubator for $24,48,72$ and $96 \mathrm{~h}$, respectively. Thereafter, cells in each well were exposed to MTT $(0.2 \mathrm{mg} / \mathrm{ml}$, Sigma-Aldrich) for $4 \mathrm{~h}$ followed by incubation with $200 \mu$ l DMSO (Sigma-Aldrich) to dissolve the dark blue crystals before reading the optical density (OD) at $490 \mathrm{~nm}$ in a microplate reader (BioTek, VT, USA). 
Wound healing assay. Cells were inoculated in 6-well plates until $80-90 \%$ confluence. A wound was gently created with a $200-\mu 1$ pipette tip on each cell monolayer, and each well was rinsed with a serum-free culture medium to remove detached cells. The migrating cells were imaged under an inverted microscope at 0,12 and $24 \mathrm{~h}$ of culturing. The result was the ratio of the migrated distance to the initial distance.

Matrigel-based invasion analysis. The Matrigel-based invasion analysis was performed in a 24-well Transwell system (Corning, Tewksbury, MA, USA) with a Matrigel (BD Biosciences, San Jose, CA, USA) pre-coated polycarbonate membrane in the top chamber. Cells were harvested and resuspended in FBS-free DMEM, then plated in the top chamber at a density of $2 \times 10^{4}$ per well. DMEM $(800 \mu \mathrm{l})$ supplemented with $30 \%$ FBS was added into the lower chamber as a chemoattractant. After $24 \mathrm{~h}$ of incubation, the non-invading cells on the upper-surface of membrane were removed with cotton swabs, and the invading cells on undersurface of the membrane were fixed with $4 \%$ paraformaldehyde for $20 \mathrm{~min}$ and stained with crystal violet for $5 \mathrm{~min}$. Invasion was analyzed in five randomly selected areas under an inverted microscope in a blinded manner.

Flow cytometry assay. Cells in each group were trypsinized, fixed with $70 \%$ ethanol, and washed with fresh medium. Thereafter, the collected MCF-7 cells were stained with FITCconjugated CD44 antibody and PE-conjugated CD24 antibody (BD Biosciences). Then the mixture was incubated for $30 \mathrm{~min}$ at room temperature in the dark. The labeled cells were washed and analyzed immediately on a FACS (fluorescence activated cell sorting) Vantage (BD Biosciences).

Aldehyde dehydrogenase (ALDH) activity assay. The Aldehyde Dehydrogenase Activity Colorimetric Assay kit (Sigma-Aldrich) was employed to analyze ALDH enzymatic activity. In brief, mammospheres were resuspended in ALDH binding buffer $\left(200 \mu 1\right.$ per $1 \times 10^{6}$ cells) then centrifuged at $13,000 \mathrm{~g}$ for $10 \mathrm{~min}$. Fifty microliters supernatant from each sample was mixed with $43 \mu \mathrm{l}$ ALDH binding buffer, $2 \mu \mathrm{l}$ ALDH substrate, and $5 \mu \mathrm{l}$ acetaldehyde in the dark. The absorbance values at OD $450 \mathrm{~nm}$ were detected at 2-3-min intervals from $5 \mathrm{~min}$ ( $\mathrm{T}$ initial) up to the standard value, the last but one absorbance value was defined as T final, and ALDH activity was calculated based on $\mathrm{T}$ initial and $\mathrm{T}$ final.

Immunofluorescence staining. Cells grown on coverslips were fixed with $4 \%$ formaldehyde for $15 \mathrm{~min}$ and permeabilized with $0.1 \%$ Triton X-100 (Amresco, Cochran Road Solon, $\mathrm{OH}$, USA) for $30 \mathrm{~min}$, cells were washed with PBS for three times at the end of each step. Subsequently, the non-specific bindings were blocked by goat serum (Solarbio) at room temperate for $15 \mathrm{~min}$. Thereafter, cells were incubated overnight at $4^{\circ} \mathrm{C}$ with primary antibody against E-cadherin (1:200 diluted, Boster, Wuhan, China) followed by incubated with Cy3-labeled goat anti-rabbit IgG secondary antibody (1:200, Beyotime, Haimen, China) for $1 \mathrm{~h}$ at room temperature. The unbound antibodies in each step were washed with PBS three times. After counterstaining with 4', 6-diamidino-2-phenylindole (DAPI) and finally rinsed with PBS, each coverslip was mounted inversely onto a slide with anti-fluorescent mounting media (Solarbio) added. Images were captured by a laser scanning confocal microscope.

$N F-\kappa B$ p 65-siRNA interference. siRNA for NF- $\kappa \mathrm{B}$ p65 and the control siRNA were designed and synthesized by GenePharma Co., Ltd. (Shanghai, China). The sequences were: NF- $\kappa$ B p65-siRNA: 5'-AGGACAUAUGAGACCUUCA-3', control siRNA: 5'-UUCUCCGAACGUGUCACGU-3'. NFp65-siRNA (75 pmol) and control siRNA were transfected into the indicated MCF-7 cells, respectively, using the Lipofectamine 2000 reagent (Invitrogen) according to the manufacturer's instructions. Cells were harvested at $24 \mathrm{~h}$ after transfection for western blot analysis.

Western blot analysis. Cells in each sample were lysed with RIPA lysate (Beyotime) including 1\% phenylmethanesulfonyl fluoride (PMSF, Beyotime). For NF- $\mathrm{B}$ p65 detection, nuclear and cytoplasmic fraction proteins were extracted using Nuclear and Cytoplasmic Protein Extraction kit (Beyotime) following the manufacturer's instructions. All protein concentrations were detected using a bicinchoninic acid (BCA) protein assay kit (Beyotime). Then equal amounts of different proteins were loaded and separated using SDS-polyacrylamide gel electrophoresis (PAGE) and electrotransferred onto polyvinylidene fluoride (PVDF) membranes (Millipore, Bedford, MA, USA). After being blocked with 5\% non-fat milk for $1 \mathrm{~h}$, the membranes were probed with primary antibodies against SDF-1, Nanog, SOX2 (all 1:200 diluted, Santa Cruz Biotechnology, Santa Cruz, CA, USA), E-cadherin, fibronectin, NF-кB p65 (all 1:400 diluted, Boster), CXCR4, CXCR7 (both 1:500 diluted, Biosharp), OCT4, Vimentin, Slug, p-IкB, IкB (all 1:500 diluted, Bioss, Beijing, China) at $4^{\circ} \mathrm{C}$ overnight and subsequently incubated with their corresponding secondary antibodies (1:5,000 dilution, Beyotime) for $45 \mathrm{~min}$ at $37^{\circ} \mathrm{C}$. Unbound antibodies in each step were washed with TBST four times. The positive bands were visualized through enhanced chemiluminescence (ECL) solution (Qihai Biotec, Shanghai, China) and measured by Gel-Pro-analyzer software (Bethesda, MD, USA). Histone $\mathrm{H} 3$ and $\beta$-actin both served as internal controls.

Statistical analysis. All values are reported as mean \pm standard deviation (SD). Kolmogorov-Smirnov (K-S) test and homogeneity of variance test were employed in each experiment and one-way analysis of variance (ANOVA) was used followed by the Bonferroni post hoc test to compare differences between groups. All statistical analysis was performed by GraphPad Prism 5.0 software. $\mathrm{P}<0.05$ was considered statistically significant.

\section{Results}

Stable overexpression of SDF-1 in breast cancer cells. To explore the potential effects of SDF-1, we first detected the expressions of SDF-1, CXCR4 and CXCR7 in MDA-MB-231, MDA-MB-435, and MCF-7 cells, respectively. Western blot analysis showed that MCF-7 cell line had the lowest expression of SDF-1 and its receptors (Fig. 1A). Hence we selected MCF-7 cell line for detailed mechanistic studies. Next, the 


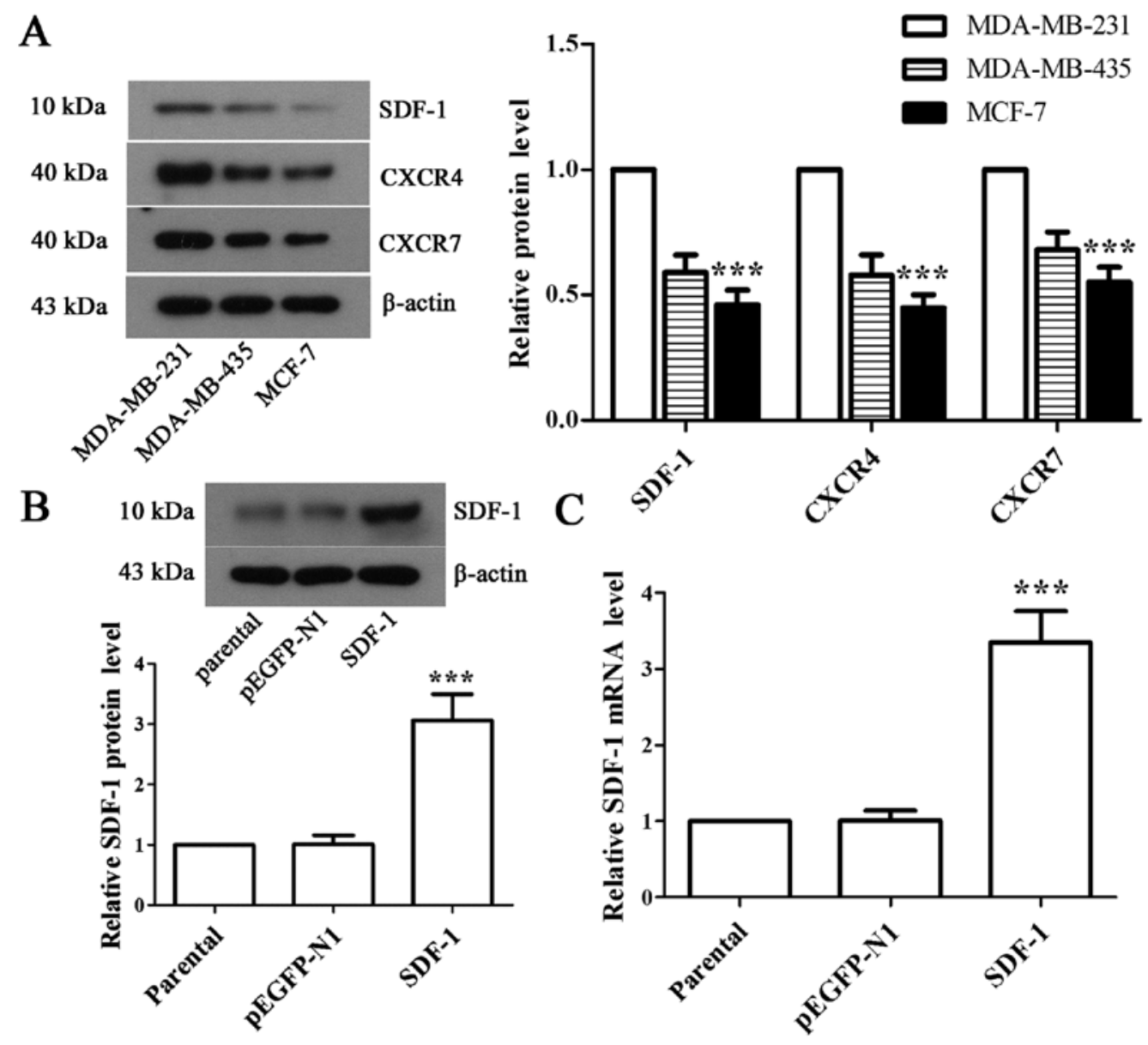

Figure 1. Stable overexpression of SDF-1 in breast cancer cells. (A) Representative photographs of western blot analysis on SDF-1, CXCR4 and CXCR7 protein expression levels in MDA-MB-231, MDA-MB-435 and MCF-7 cells. $\beta$-actin was used as an internal control. ${ }^{* * *} \mathrm{P}<0.001$ vs MDA-MB-231. (B) The pEGFP-N1-SDF-1 plasmid was transfected into MCF-7 cells, and the protein expression level of SDF-1 in MCF-7 cells was detected by western blot analysis and normalized to $\beta$-actin. The typical blots are shown, and the parental MCF-7 cells and pEGFP-N1 transfected MCF-7 cells served as controls. ${ }^{* * *} \mathrm{P}<0.001$ vs pEGFP-N1. (C) Real-time (RT) PCR analysis of SDF-1 mRNA expression levels. ${ }^{* * * *} \mathrm{P}<0.001$ vs pEGFP-N1. The above results are given as mean \pm SD, and the error bars represent the SD from three independent experiments.

recombinant pEGFP-N1-SDF-1 plasmid was transfected into MCF-7 cells, and western blot analysis and RT-PCR were performed to validate the expression of SDF-1 in positive monoclonal cells. The results showed that the expression of SDF-1 was increased by 3.03 -fold (Fig. 1B, P<0.001) and 3.32-fold (Fig. 1B, $\mathrm{P}<0.001$ ) at protein and mRNA levels, respectively, in SDF-1-transfected MCF-7 cells compared with pEGFP-N1-transfected MCF-7 cells, which suggested stable overexpression of SDF-1 in MCF-7 cell line.

Overexpression of $S D F-1$ promotes the proliferation, migration and invasion of MCF-7 cells. Colony formation and MTT assay were employed to visualize the effect of SDF-1 on the proliferation of MCF-7 cells. We found that the colony formation rate in overexpressing SDF-1 MCF-7 cells was enhanced by 1.54 -fold compared with parental (Fig. $2 \mathrm{~A}, \mathrm{P}<0.01$ ). At the same time, the proliferation capability of MCF-7 cells with SDF-1 transfection was increased significantly from 48 to $96 \mathrm{~h}$ as compared to parental (Fig. $2 \mathrm{~B}, \mathrm{P}<0.05$ ). The above results indicated that SDF-1 was able to enhance the proliferation of MCF-7 cells.

We further evaluated the effect of SDF-1 on the migratory and invasive potential of MCF-7 cells through wound healing and Transwell assay. The results at 12 and $24 \mathrm{~h}$ after wounding both showed that the wound healing rate in SDF-1- overexpressed MCF-7 cells was notably elevated compared with parental (Fig. 2C, $\mathrm{P}<0.01$ ). Moreover, the number of invading cells was $54 \pm 5.7$ in SDF-1 overexpressed-MCF-7 cells in the present of FBS, which was increased compared with parental $(27.6 \pm 2.7)$ (Fig. 2D, $\mathrm{P}<0.001)$. Thus, the results strongly supported that overexpression of SDF-1 could promote migration and invasion of MCF-7 cells.

Overexpression of SDF-1 induces CSC-like phenotype formation from MCF-7 cells. To observe whether overexpression of SDF-1 contributes to the formation of CSC-like phenotypes in MCF-7 cells, we detected the proportion of CD $44^{+} / \mathrm{CD} 24$ cells through flow cytometry. Our analysis showed that SDF-1 caused an increased accumulation of cell population with CD $44^{+} / \mathrm{CD} 24^{-}$phenotype (Fig. 3A, P<0.01). Similarly, ALDH activity was also dramatically elevated by overexpressing SDF-1 in MCF-1 cells (Fig. 3B, $\mathrm{P}<0.01$ ). It was further observed that the expression of OCT-4, Nanog, and SOX2 in both mRNA and protein levels was elevated significantly in SDF-1-overexpressed MCF-7 cells compared with parental as observed by RT-PCR and western blot analysis (Fig. 3C and D, 

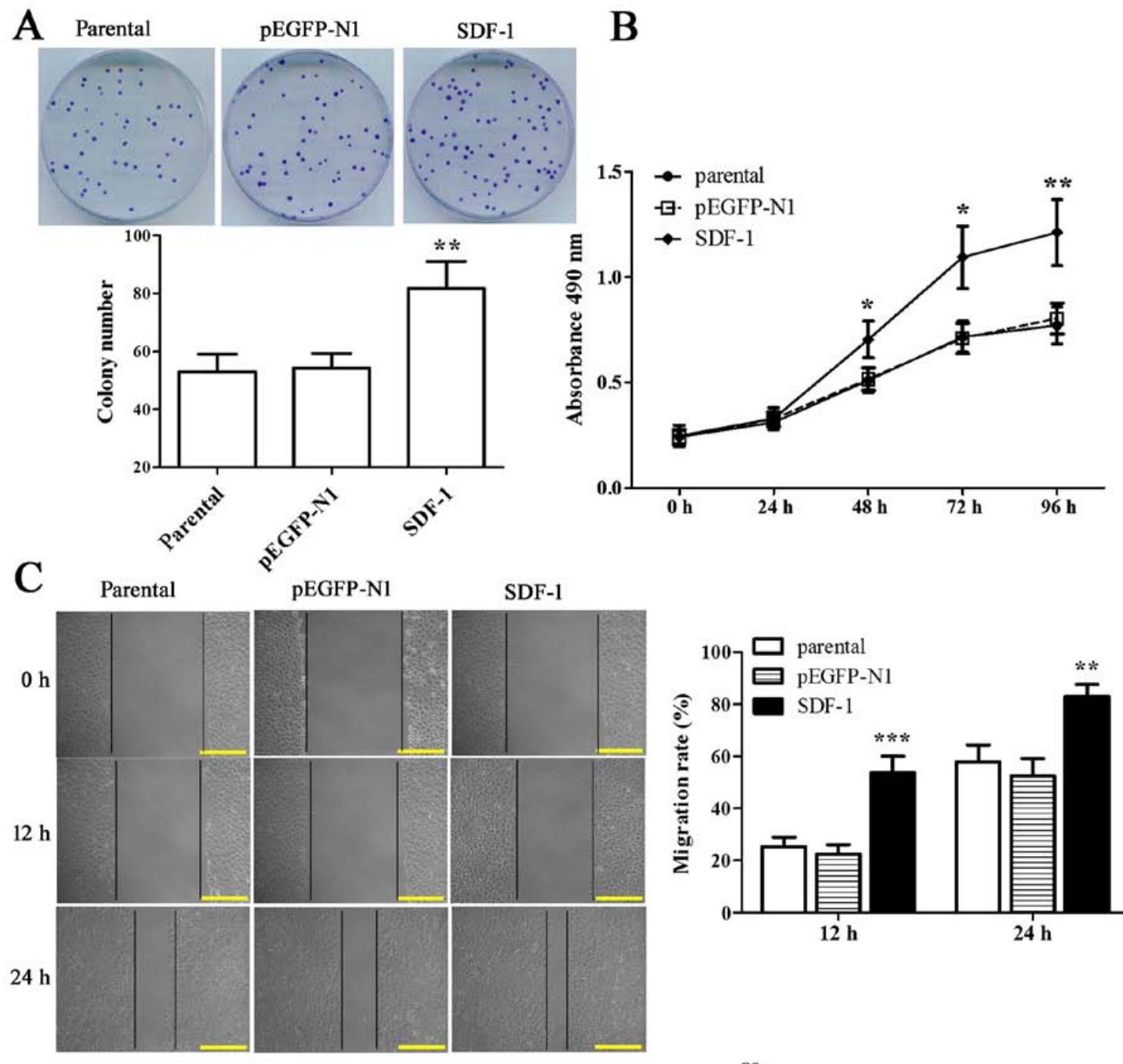

D

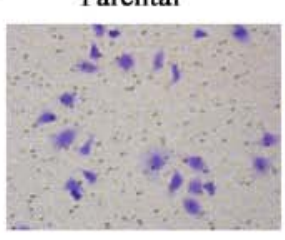

pEGFP-N1

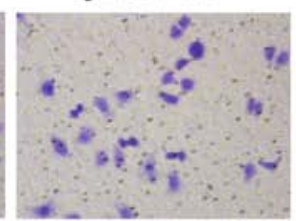

SDF-1

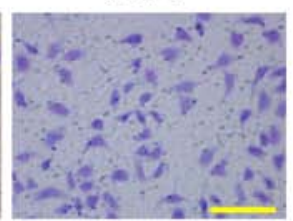

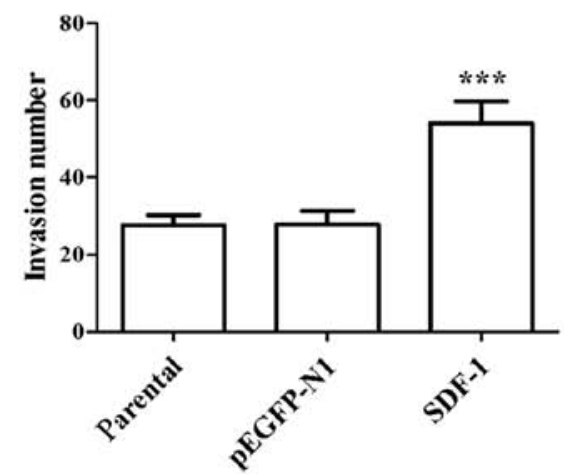

Figure 2. Overexpression of SDF-1 promotes the proliferation, migration and invasion of MCF-7 cells. (A) Cells were seeded in 35-mm plates and incubated for 14 days before being fixed with $4 \%$ formaldehyde. Then the cells were stained with Wright-Giemsa dye composite to calculate the number of colony formation, and the representative images are shown. (B) Cells were plated in 96-well plates with five replicates for each testing point and cultured for $24,48,72$ and $96 \mathrm{~h}$, respectively. MTT assay was used to evaluate cell viability at OD $490 \mathrm{~nm}$. (C) A wound was created on cell monolayer in each well, cells were cultured for 12 or $24 \mathrm{~h}$, and the distance migrated was measured. Representative photomicrographs are shown on the left. Scale bars indicate $200 \mu \mathrm{m}$ at $\mathrm{x} 200 \mathrm{magnification}$. (D) The Matrigel-based invasion assay was carried out in a Transwell system. After $24 \mathrm{~h}$ of incubation, the invading cells on undersurface of the membrane were fixed with $4 \%$ paraformaldehyde, stained with crystal violet and counted with five randomly selected microscopic fields. Representative examples of photographs are shown on the left. Scale bar indicates $200 \mu \mathrm{m}$ at x 200 magnification. Experiments were all done in triplicates for statistical significance, and the results are expressed as mean $\pm \mathrm{SD} .{ }^{*} \mathrm{P}<0.05,{ }^{* *} \mathrm{P}<0.01,{ }^{* * *} \mathrm{P}<0.001$ vs parental.

$\mathrm{P}<0.01)$. These results suggested that MCF-7 cells obtained the CSC-like phenotype by overexpressing SDF-1.

Overexpression of SDF-1 boosts EMT of MCF-7 cells. To address the effect of SDF-1 on EMT of MCF-7 cells, we first observed the loose connections between cells with SDF-1 overexpression (Fig. 4A). Then we identified the significantly downregulated E-cadherin and notably upregulated slug, fibronectin and vimentin in SDF-1-overexpressed MCF-7 cells compared with parental (Fig. 4B, D and E, P<0.01). 
A
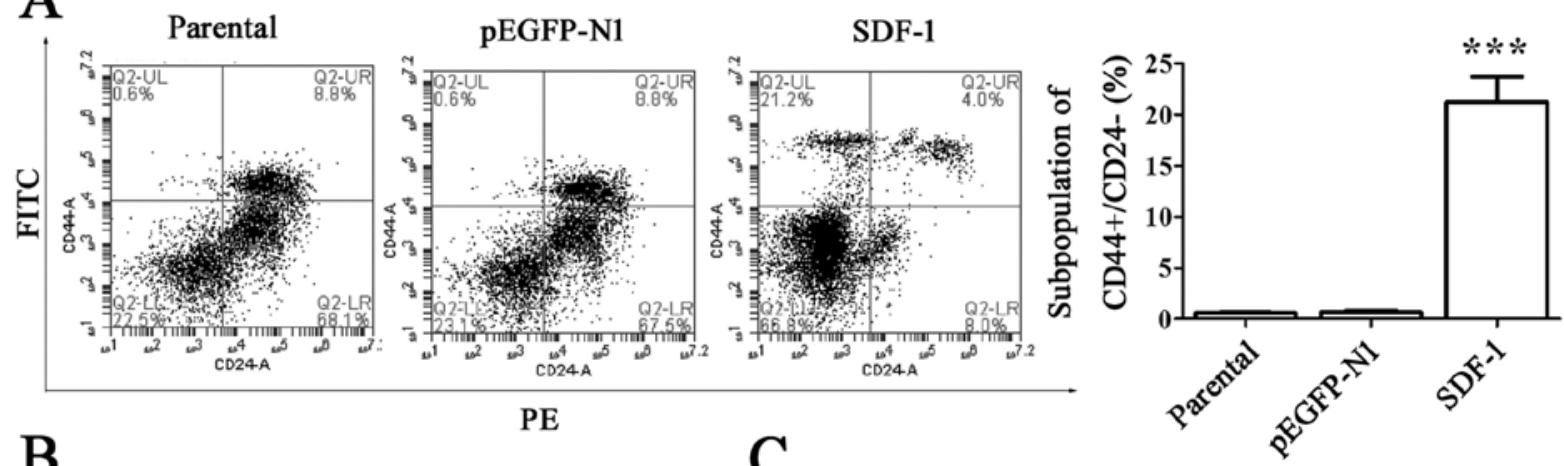

B

PE
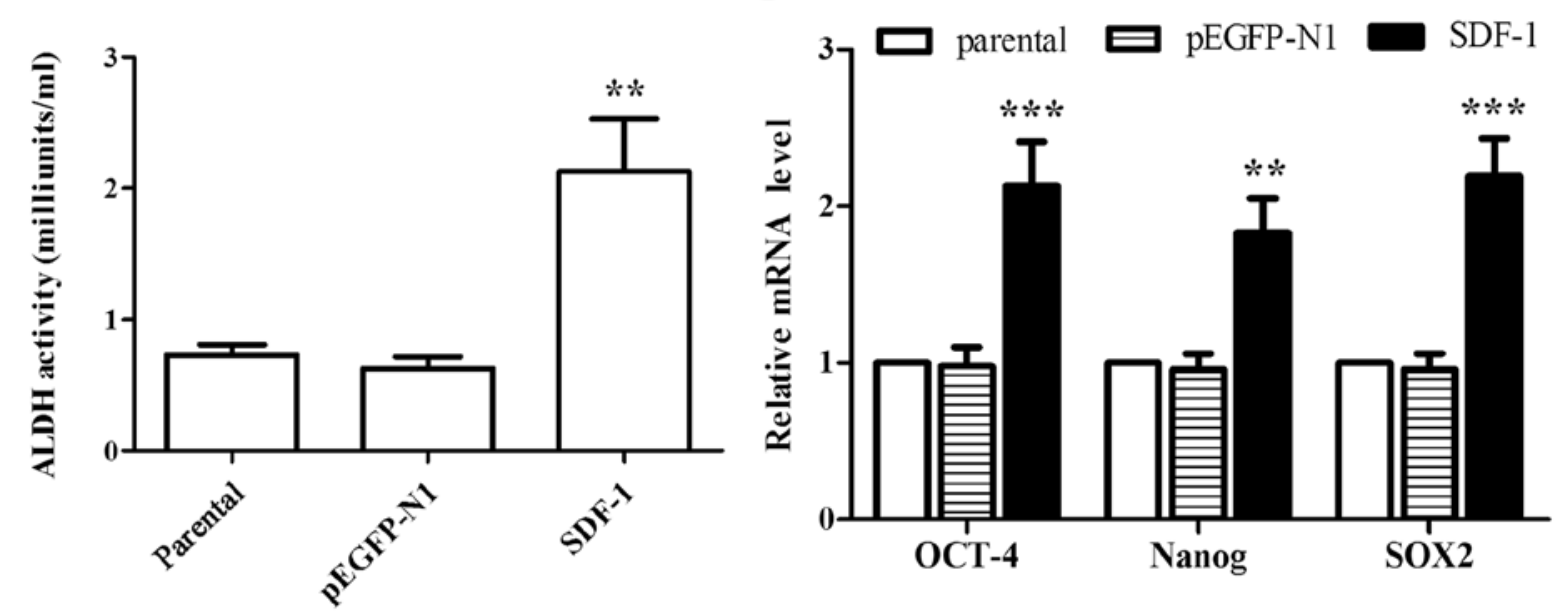

D
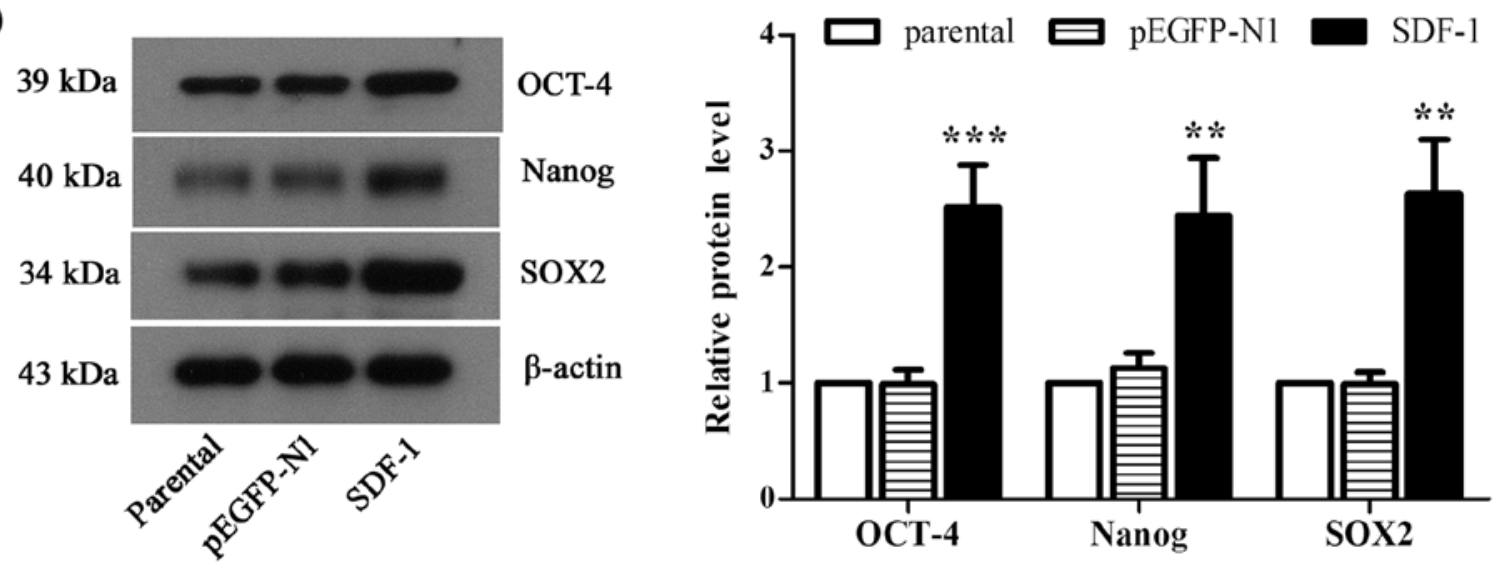

Figure 3. Overexpression of SDF-1 induces CSC-like phenotype formation from MCF-7 cells. (A) Transwell MCF-7 cells were stained with FITC-conjugated CD44 antibody and PE-conjugated CD24 antibody. The percentage of different CD44/CD24 subpopulations was determined by flow cytometry assay. A series of representative illustrations of cell subpopulation distributions are shown. (B) Colorimetry was carried out to assess ALDH activity in mammospheres at OD $450 \mathrm{~nm}$. (C) Relative mRNA levels of OCT-4, Nanog, and SOX2 were evaluated by RT-PCR. (D) Relative protein levels of OCT-4, Nanog, and SOX2 were evaluated by western blot analysis, and the representative images are shown. $\beta$-actin served as internal control. The above two experiments were repeated three times. Data are presented as mean $\pm \mathrm{SD} .{ }^{* *} \mathrm{P}<0.01,{ }^{* * *} \mathrm{P}<0.001$ vs parental.

Accordingly, the fluorescence intensity of E-cadherin was appeared to be reduced obviously in SDF-1 overexpressedMCF-7 cells as compared with parental (Fig. 4C). Collectively, these data revealed that overexpression of SDF-1 could induce EMT in MCF-7 cells.

$N F-\kappa B$ pathway is involved in SDF-1-mediated EMT in MCF-7 cells. To investigate the mechanism by which SDF-1 induced EMT in MCF-7 cells, western blot analysis was applied to examine the expression levels of related proteins in $\mathrm{NF}-\kappa \mathrm{B}$ pathway. We discovered a apparent decrease of cytoplasmic p65 level and a significant increase of nuclear p65 level in SDF-1 overexpressed MCF-7 cells compared with parental (Fig. 5A, $\mathrm{P}<0.01$ ), along with the notably elevated phosphorylation level of cytoplasmic I $\kappa \mathrm{B}$ (Fig. 5B, P<0.001), suggesting the activation of NF- $\kappa$ B pathway. We further employed BAY 11-7028, an antagonist target $\mathrm{NF}-\kappa \mathrm{B}$ pathway, to inhibit $\mathrm{NF}-\kappa \mathrm{B}$ pathway, and performed siRNA interference to silence $N F-\kappa B$ p 65 gene in SDF-1 overexpressed-MCF-7 cells. Both results showed the significantly upregulated E-cadherin expression (Fig. 5C 
A
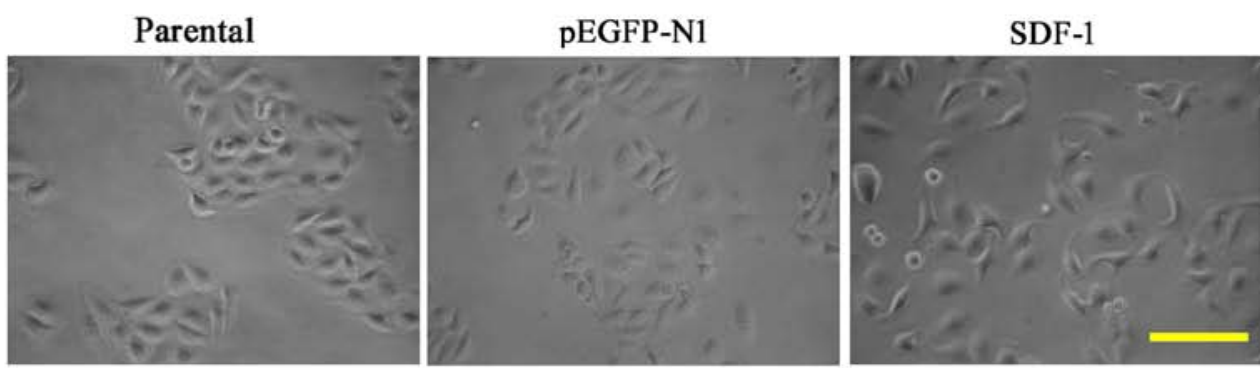

B
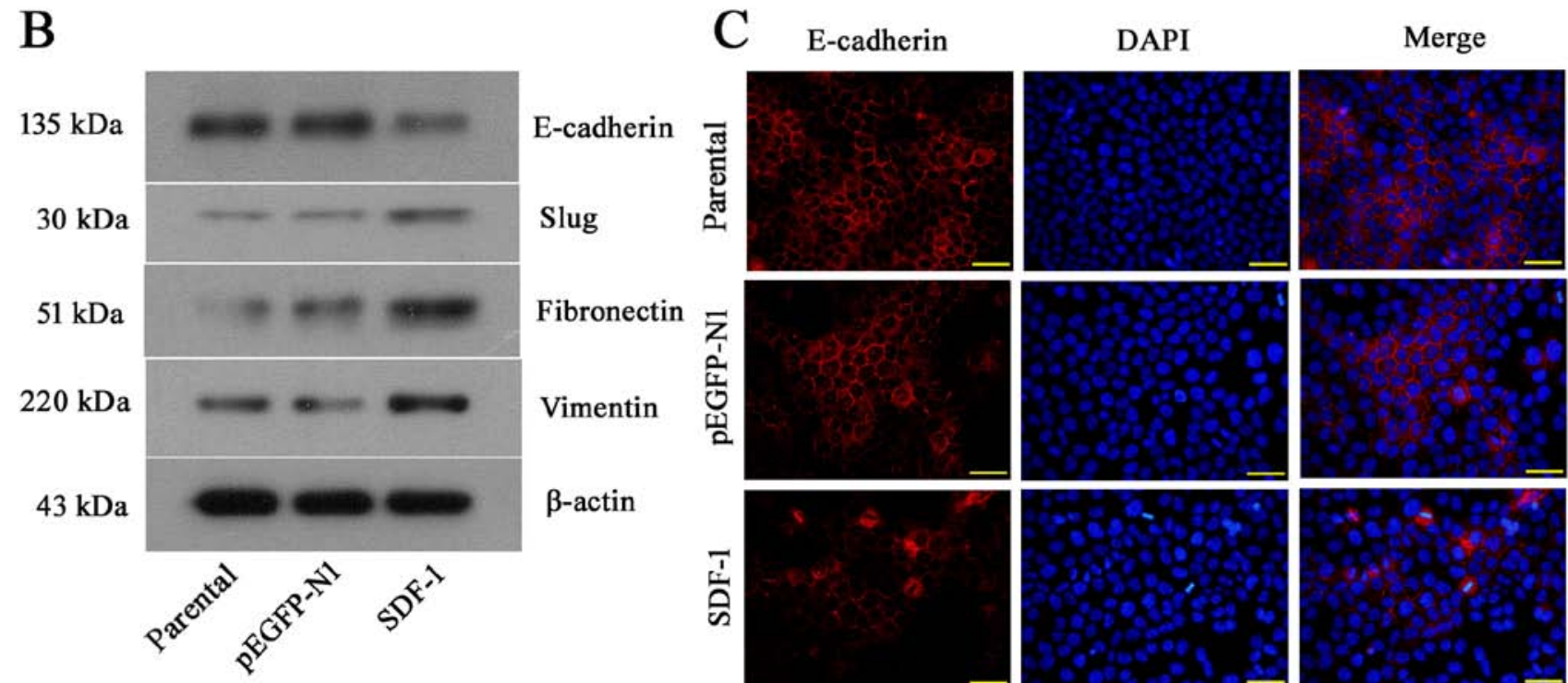

$\beta$-actin
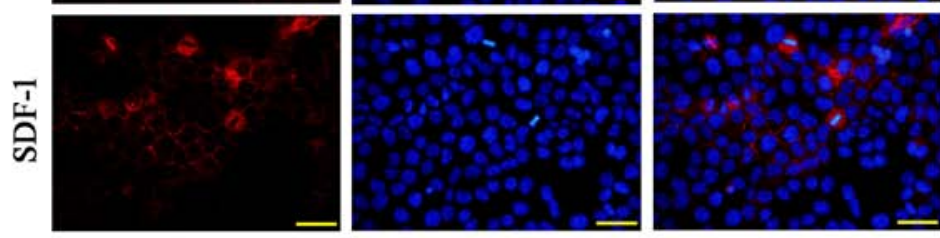

D

E
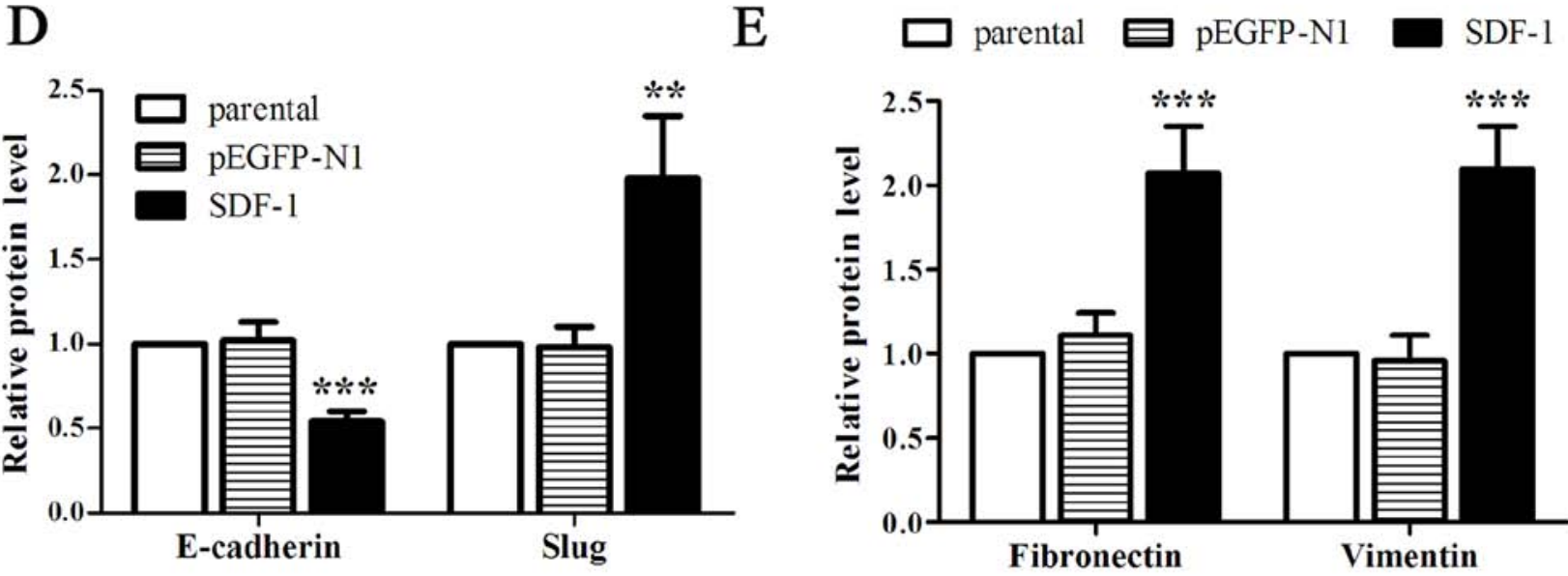

Fibronectin

Vimentin

Figure 4. Overexpression of SDF-1 boosts EMT of MCF-7 cells. (A) Representative photomicrographs of MCF-7 cells in each group under phase contrast microscope. Scale bars, $200 \mu \mathrm{m}$. (B) Representative blots of E-cadherin, slug, fibronectin and vimentin, and $\beta$-actin was used as internal control. (C) Immunofluorescence staining was performed to investigate the expression of E-cadherin. Representative immunofluorescence images are shown. E-cadherin was visualized with Cy3-labeled red by goat anti-rabbit IgG, and cell nuclei were stained blue by DAPI. Scale bar indicates $100 \mu \mathrm{m}$ at $\mathrm{x} 400$ magnification. (D) Relative protein levels of E-cadherin and slug were measured by gray scale analysis. (E) Relative protein levels of fibronectin and vimentin were measured by gray scale analysis. Data in each group are given as mean $\pm \mathrm{SD}$ from three independent experiments. ${ }^{* *} \mathrm{P}<0.01,{ }^{* * * *} \mathrm{P}<0.001 \mathrm{vs}$ parental.

and $\mathrm{D}, \mathrm{P}<0.001)$, which indicated that $\mathrm{NF}-\kappa \mathrm{B}$ played a prominent role in the progression of EMT in SDF-1 overexpressed breast cancer cells.

\section{Discussion}

SDF-1 is involved in a broad range of biological procedures including cell adhesion, migration, invasion, chemotaxis, cell cycle, proliferation, apoptosis, angiogenesis, and cell commu- nication. However, whether SDF-1 could induce CSC-like phenotypes and EMT of breast cancer cells and the detailed mechanism remain unclear. Here, we overexpressed SDF-1 in the poorly invasive MCF-7 cells (23). Then we found that overexpressing SDF-1 could trigger EMT in MCF-7 cells by activating $\mathrm{NF}-\kappa \mathrm{B}$ pathway and induce $\mathrm{CSC}$-like phenotypes to increase the abilities of proliferation, migration, and invasion. Overall, these results further identified the roles of SDF-1 in the metastases of breast cancer cells. 

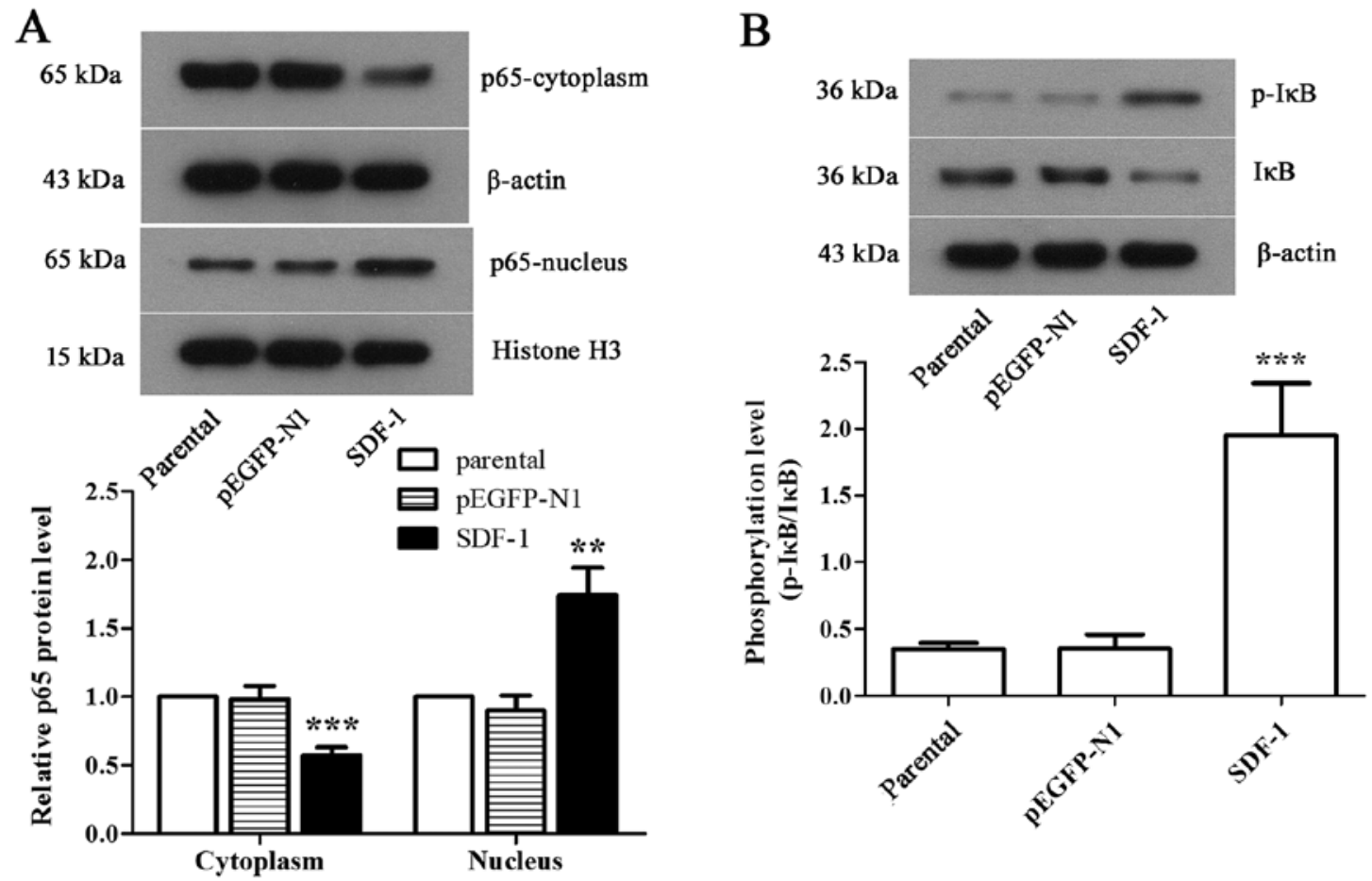

C
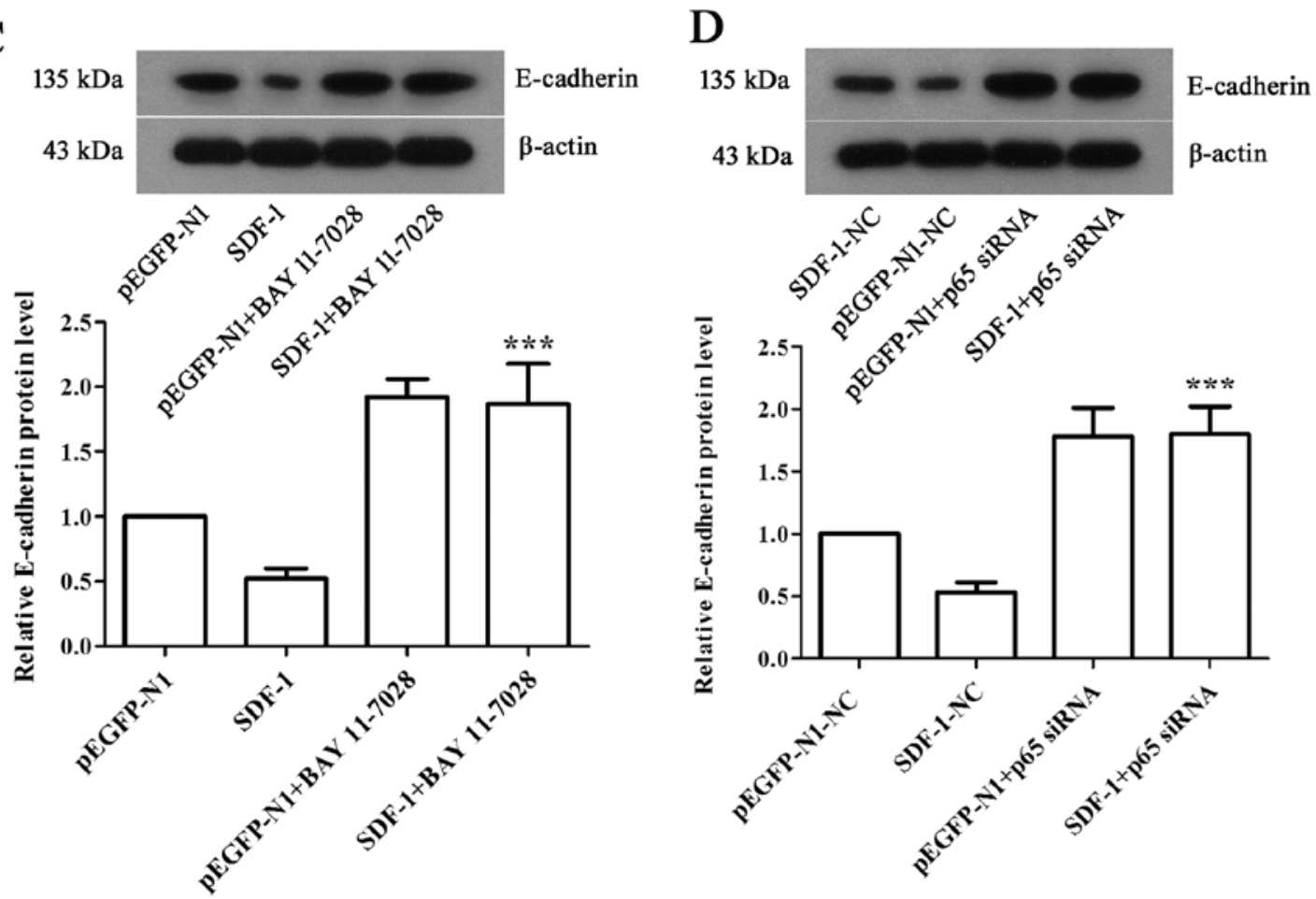

Figure 5. NF-кB pathway is involved in SDF-1-mediated EMT in MCF-7 cells. (A) Western blot analysis on the expression of p65 in cytoplasm and nucleus. (B) Western blot analysis on the phosphorylation level of IкB. (C) pEGFP-N1 transfected cells and SDF-1 transfected cells were both treated with BAY 11-7028 for $48 \mathrm{~h}$, then western blot analysis was employed to detect the expression of E-cadherin in MCF-7 cells. (D) p65 gene in both pEGFP-N1 transfected cells and SDF-1 transfected cells was silenced by RNA interference, and western blot analysis was used to examine the expression of E-cadherin in MCF-7 cells. Representative blots are all presented and corresponding gray scale analysis is shown as mean \pm SD of three independent experiments. $\beta$-actin and histone $\mathrm{H} 3$ served as internal controls. ${ }^{* *} \mathrm{P}<0.01,{ }^{* * *} \mathrm{P}<0.001$ vs parental.

The interactions between SDF-1 and receptors CXCR4 and CXCR7 control multiple steps of tumor growth and metastasis in $>20$ human malignancies, including breast cancer (24). In addition, overexpression of SDF-1 can recruit more macrophages. The increased recruitment of cancerassociated macrophages (CAMs) is not contributed only to tumor angiogenesis by releasing vascular endothelial growth factor (VEGF) but also capable of inducing tumor cell motility and invasion through paracrine loop signaling (25-28). On the contrary, hypoxia has been reported as an important driving force for the multistep process of metastasis, and the accumulated CAMs could exacerbate the oxidant microenvironment 
of the tumor. Hypoxia improves metastatic seeding of cancer cells by enhancing CXCR4 expression to enable tumor cells to home to SDF1 highly expressed secondary organs (29). In our study, we created an autocrine loop of SDF-1 and its receptors and found that overexpression of SDF-1 could increase the growth, migration, and invasion in MCF-7 cells without recruiting CAMs, consistent with Kang and colleagues (30).

CSCs are unresponsive to chemotherapeutic and apoptotic drugs since they can resist DNA damage (30). Breast cancer stem cells (BCSCs) have been identified as CD $44^{+} / \mathrm{CD} 24$ cells. Huang et al reported that SDF-1 boosted the proliferation of $\mathrm{CD} 44^{+} / \mathrm{CD} 24^{-}$cells through SDF-1/CXCR4 signaling (1). We found that the subpopulation of $\mathrm{MCF}-7$ cells with CD $44^{+} / \mathrm{CD} 24^{-}$phenotypes was elevated after overexpressing SDF-1, suggesting the acquirement of CSC phenotypes in overexpressing SDF-1 MCF-7 cells. ALDH1 exhibits low or absent expression in normal breast tissue, breast cells with increased ALDH1 expression indicate stem or progenitor properties with broadest differentiation potential and greatest growth capacity (31). The transcription factors OCT4, Nanog and SOX2 are all embryonic stem cell (ESC) markers and play an important role in maintaining the pluripotent self-renewal of ESCs, which are downregulated in the differentiated somatic cells (32). In response to hypoxic conditions, hypoxiainducible factors (HIFs) reprogram non-stem cancer cells to a stem-like phenotype by increasing the transcription of ALDH and inducing the expression of OCT4 and Nanog $(33,34)$. Here, in vitro, the mammosphere cells with increased ALDH activity was observed, along with the upregulation of OCT4, Nanog and SOX2 in SDF-1 overespressed MCF-7 cells, suggesting that SDF-1 could induce CSC-like phenotypes of breast cancer cells. It has been indicated that the emergence of CSCs occurs in part because of EMT (5). Hence, further experiments were required to identify the effect of SDF-1 on EMT in MCF-7 cells.

E-cadherin is an epithelial cell junction marker; vimentin and fibronectin are mesenchymal markers. During the progression of EMT, slug could repress E-cadherin transcription at promoter level to break down the adherence junction $(7,35)$. In this study, we found that overexpression of SDF-1 increased the expression of slug leading to downregulation of E-cadherin, along with the elevated expression of vimentin and fibronectin, suggesting that EMT was triggered by overexpressing SDF-1 which may subsequently induced CSC phenotypes in MCF-7 cells to facilitated breast cancer cells metastasis.

$\mathrm{NF}-\kappa \mathrm{B}$ pathway is associated with cell proliferation, apoptosis, and inflammation, and involved in diverse progressions of cancer development $(36,37)$. Recent studies have identified that NF- $\kappa \mathrm{B}$ was an important regulator of EMT in several cell types (38-40) governing the induction, metastasis and maintenance of EMT (41). Jiang et al reported that longer times for EMT would increase activation of $\mathrm{I} \kappa \mathrm{B}$ and $\mathrm{NF}-\kappa \mathrm{B}$, then the expression of stem cell markers were enhanced to promote neoplastic transformation of human keratinocytes (42). It is a well established fact that the promoter of CXCR4 contains several binding sites for $\mathrm{NF}-\kappa \mathrm{B}$, we therefore speculated that $\mathrm{NF}-\kappa \mathrm{B}$ pathway may be involved in SDF-1-induced EMT of $\mathrm{MCF}-7$ cells. Our results showed the activation of $\mathrm{NF}-\kappa \mathrm{B}$ pathway in SDF-1 overexpressing MCF-7 cells, and the expression of E-cadherin was increased remarkably after incubating with NF- $\mathrm{NB}$ inhibitor drug or silencing $\mathrm{NF}-\kappa \mathrm{B}$ p 65 gene in $\mathrm{SDF}-1-$ overexpressed $\mathrm{MCF}-7$ cells, indicating that $\mathrm{NF}-\kappa \mathrm{B}$ pathway regulates SDF-1-induced EMT of breast cancer cells. For the downstream pathways of SDF-1/CXCR4 in breast CSCs, Yi et al identified SDF-1/CXCR4-PKA-MAP2K2-ERK signaling pathway and demonstrated the feedback regulation on MEK, ERK1/2, $\delta$-catenin, and PPP1C $\alpha$ in breast CSCs treated with $100 \mathrm{ng} / \mathrm{ml} \mathrm{SDF}-1$ (43). As EMT is an important inducer of CSCs, there must be connections between $\mathrm{NF}-\kappa \mathrm{B}$ pathway and PKA-MAP2K2-ERK signaling pathway which is one of the strategies of our subsequent study.

In conclusion, our data indicated that overexpression of SDF-1 could trigger EMT of MCF-7 cells through NF- $\mathrm{B}$ pathway to further gain the CSC-like phenotypes, subsequently promoting metastasis of MCF-7 cells. Our findings preliminarily identified the significant roles of SDF-1 in MCF-1 cells, and suggest that SDF-1 may become a promising candidate for breast cancer therapy.

\section{Acknowledgements}

This study was supported by a grant from the National Nature Science Foundation of China (no. 81371564).

\section{References}

1. Huang M, Li Y, Zhang $\mathrm{H}$ and Nan F: Breast cancer stromal fibroblasts promote the generation of CD44 CD24- cells through SDF-1/CXCR4 interaction. J Exp Clin Cancer Res 29: 80, 2010.

2. Guerrero-Preston R, Hadar T, Ostrow KL, Soudry E, Echenique M, Ili-Gangas C, Pérez G, Perez J, Brebi-Mieville P, Deschamps J, et al: Differential promoter methylation of kinesin family member 1a in plasma is associated with breast cancer and DNA repair capacity. Oncol Rep 32: 505-512, 2014.

3. Pang H, Lu H, Song H, Meng Q, Zhao Y, Liu N, Lan F, Liu Y, Yan S, Dong X, et al: Prognostic values of osteopontin-c, E-cadherin and $\beta$-catenin in breast cancer. Cancer Epidemiol 37: 985-992, 2013.

4. Al-Hajj M, Wicha MS, Benito-Hernandez A, Morrison SJ and Clarke MF: Prospective identification of tumorigenic breast cancer cells. Proc Natl Acad Sci USA 100: 3983-3988, 2003.

5. Singh A and Settleman J: EMT, cancer stem cells and drug resistance: An emerging axis of evil in the war on cancer. Oncogene 29: 4741-4751, 2010 .

6. Liu L, Salnikov AV, Bauer N, Aleksandrowicz E, Labsch S Nwaeburu C, Mattern J, Gladkich J, Schemmer P, Werner J, et al: Triptolide reverses hypoxia-induced epithelial-mesenchymal transition and stem-like features in pancreatic cancer by NF-kappaB downregulation. Int J Cancer 134: 2489-2503, 2014.

7. Jethwa P, Naqvi M, Hardy RG, Hotchin NA, Roberts S, Spychal R and Tselepis C: Overexpression of Slug is associated with malignant progression of esophageal adenocarcinoma. World $\mathrm{J}$ Gastroenterol 14: 1044-1052, 2008.

8. Sánchez-Martín L, Sánchez-Mateos P and Cabañas C: CXCR7 impact on CXCL12 biology and disease. Trends Mol Med 19: 12-22, 2013.

9. Luker KE and Luker GD: Functions of CXCL12 and CXCR4 in breast cancer. Cancer Lett 238: 30-41, 2006.

10. Ray P, Lewin SA, Mihalko LA, Lesher-Perez SC, Takayama S, Luker KE and Luker GD: Secreted CXCL12 (SDF-1) forms dimers under physiological conditions. Biochem J 442: 433-442, 2012.

11. Papatheodorou H, Papanastasiou AD, Sirinian C, Scopa C, Kalofonos HP, Leotsinidis $\mathrm{M}$ and Papadaki $\mathrm{H}$ : Expression patterns of SDF1/CXCR4 in human invasive breast carcinoma and adjacent normal stroma: Correlation with tumor clinicopathological parameters and patient survival. Pathol Res Pract 210: 662-667, 2014.

12. Hinton CV, Avraham S and Avraham HK: Role of the CXCR4/ CXCL12 signaling axis in breast cancer metastasis to the brain. Clin Exp Metastasis 27: 97-105, 2010. 
13. Sun Y, Mao X, Fan C, Liu C, Guo A, Guan S, Jin Q, Li B, Yao F and Jin F: CXCL12-CXCR4 axis promotes the natural selection of breast cancer cell metastasis. Tumour Biol 35: 7765-7773, 2014.

14. Nagasawa T, Kikutani $\mathrm{H}$ and Kishimoto T: Molecular cloning and structure of a pre-B-cell growth-stimulating factor. Proc Natl Acad Sci USA 91: 2305-2309, 1994.

15. Müller A, Homey B, Soto H, Ge N, Catron D, Buchanan ME McClanahan T, Murphy E, Yuan W, Wagner SN, et al: Involvement of chemokine receptors in breast cancer metastasis. Nature 410: 50-56, 2001.

16. Phillips RJ, Burdick MD, Lutz M, Belperio JA, Keane MP and Strieter RM: The stromal derived factor-1/CXCL12-CXC chemokine receptor 4 biological axis in non-small cell lung cancer metastases. Am J Respir Crit Care Med 167: 1676-1686, 2003.

17. Williams SA, Harata-Lee Y, Comerford I, Anderson RL, Smyth MJ and McColl SR: Multiple functions of CXCL12 in a syngeneic model of breast cancer. Mol Cancer 9: 250, 2010.

18. Hattermann K, Holzenburg E, Hans F, Lucius R, Held-Feindt J and Mentlein R: Effects of the chemokine CXCL12 and combined internalization of its receptors CXCR4 and CXCR7 in human MCF-7 breast cancer cells. Cell Tissue Res 357: 253-266, 2014.

19. Gao Z, Wang X, Wu K, Zhao Y and Hu G: Pancreatic stellate cells increase the invasion of human pancreatic cancer cells through the stromal cell-derived factor-1/CXCR4 axis. Pancreatology 10: 186-193, 2010

20. Jiang YP, Wu XH, Xing HY and Du XY: Effect of chemokine CXCL12 and its receptor CXCR4 on proliferation, migration and invasion of epithelial ovarian cancer cells. Zhonghua Fu Chan $\mathrm{Ke}$ Za Zhi 42: 403-407, 2007 (In Chinese).

21. Kang H, Watkins G, Parr C, Douglas-Jones A, Mansel RE and Jiang WG: Stromal cell derived factor-1: Its influence on invasiveness and migration of breast cancer cells in vitro, and its association with prognosis and survival in human breast cancer. Breast Cancer Res 7: R402-R410, 2005.

22. Wang R, Lv Q, Meng W, Tan Q, Zhang S, Mo X and Yang X: Comparison of mammosphere formation from breast cancer cell lines and primary breast tumors. J Thorac Dis 6: 829-837, 2014.

23. Bae SN, Arand G, Azzam H, Pavasant P, Torri J, Frandsen TL and Thompson EW: Molecular and cellular analysis of basement membrane invasion by human breast cancer cells in Matrigelbased in vitro assays. Breast Cancer Res Treat 24: 241-255, 1993

24. Luker KE, Lewin SA, Mihalko LA, Schmidt BT, Winkler JS Coggins NL, Thomas DG and Luker GD: Scavenging of CXCL12 by CXCR7 promotes tumor growth and metastasis of CXCR4-positive breast cancer cells. Oncogene 31: 4750-4758, 2012.

25. Boimel PJ, Smirnova T, Zhou ZN, Wyckoff J, Park H, Coniglio SJ, Qian BZ, Stanley ER, Cox D, Pollard JW, et al: Contribution of CXCL12 secretion to invasion of breast cancer cells. Breast Cancer Res 14: R23, 2012.

26. Goswami S, Sahai E, Wyckoff JB, Cammer M, Cox D, Pixley FJ, Stanley ER, Segall JE and Condeelis JS: Macrophages promote the invasion of breast carcinoma cells via a colony-stimulating factor-1/epidermal growth factor paracrine loop. Cancer Res 65: 5278-5283, 2005.

27. Porcile C, Bajetto A, Barbieri F, Barbero S, Bonavia R, Biglieri M, Pirani P, Florio T and Schettini G: Stromal cell-derived factor1alpha (SDF-1alpha/CXCL12) stimulates ovarian cancer cell growth through the EGF receptor transactivation. Exp Cell Res 308: 241-253, 2005.
28. Porta C, Subhra Kumar B, Larghi P, Rubino L, Mancino A and Sica A: Tumor promotion by tumor-associated macrophages. Adv Exp Med Biol 604: 67-86, 2007.

29. Kucia M, Ratajczak J and Ratajczak MZ: Bone marrow as a source of circulating CXCR4 ${ }^{+}$tissue-committed stem cells. Biol Cell 97: 133-146, 2005.

30. Mukherjee D and Zhao J: The role of chemokine receptor CXCR4 in breast cancer metastasis. Am J Cancer Res 3: 46-57, 2013.

31. Ginestier C, Hur MH, Charafe-Jauffret E, Monville F, Dutcher J, Brown M, Jacquemier J, Viens P, Kleer CG, Liu S, et al: ALDH1 is a marker of normal and malignant human mammary stem cells and a predictor of poor clinical outcome. Cell Stem Cell 1: 555-567, 2007.

32. Ogony JW, Malahias E, Vadigepalli R and Anni H: Ethanol alters the balance of Sox2, Oct4, and Nanog expression in distinct subpopulations during differentiation of embryonic stem cells. Stem Cells Dev 22: 2196-2210, 2013.

33. Brahimi-Horn MC, Chiche J and Pouysségur J: Hypoxia and cancer. J Mol Med Berl 85: 1301-1307, 2007.

34. Heddleston JM, Li Z, McLendon RE, Hjelmeland AB and Rich JN: The hypoxic microenvironment maintains glioblastoma stem cells and promotes reprogramming towards a cancer stem cell phenotype. Cell Cycle 8: 3274-3284, 2009.

35. Bolós V, Peinado H, Pérez-Moreno MA, Fraga MF, Esteller M and Cano A: The transcription factor Slug represses E-cadherin expression and induces epithelial to mesenchymal transitions: A comparison with Snail and E47 repressors. J Cell Sci 116: 499-511, 2003.

36. Maier HJ, Schmidt-Strassburger U, Huber MA, Wiedemann EM, Beug $\mathrm{H}$ and Wirth T: NF-kappaB promotes epithelialmesenchymal transition, migration and invasion of pancreatic carcinoma cells. Cancer Lett 295: 214-228, 2010.

37. Karin $\mathrm{M}$ and Greten FR: NF-kappaB: Linking inflammation and immunity to cancer development and progression. Nat Rev Immunol 5: 749-759, 2005.

38. Chua HL, Bhat-Nakshatri P, Clare SE, Morimiya A, Badve S and Nakshatri H: NF-kappaB represses E-cadherin expression and enhances epithelial to mesenchymal transition of mammary epithelial cells: Potential involvement of ZEB-1 and ZEB-2. Oncogene 26: 711-724, 2007.

39. Min C, Eddy SF, Sherr DH and Sonenshein GE: NF-kappaB and epithelial to mesenchymal transition of cancer. J Cell Biochem 104: 733-744, 2008.

40. Shin SR, Sánchez-Velar N, Sherr DH and Sonenshein GE: 7,12-dimethylbenz(a)anthracene treatment of a c-rel mouse mammary tumor cell line induces epithelial to mesenchymal transition via activation of nuclear factor-kappaB. Cancer Res 66: 2570-2575, 2006.

41. Huber MA, Beug H and Wirth T: Epithelial-mesenchymal transition: NF-kappaB takes center stage. Cell Cycle 3: 1477-1480, 2004.

42. Jiang R, Li Y, Xu Y, Zhou Y, Pang Y, Shen L, Zhao Y, Zhang J, Zhou J, Wang X, et al: EMT and CSC-like properties mediated by the IKK $\beta / \mathrm{I} \kappa \mathrm{B} \alpha /$ RelA signal pathway via the transcriptional regulator, Snail, are involved in the arsenite-induced neoplastic transformation of human keratinocytes. Arch Toxicol 87: 991-1000, 2013.

43. Yi T, Zhai B, Yu Y, Kiyotsugu Y, Raschle T, Etzkorn M, Seo HC, Nagiec M, Luna RE, Reinherz EL, et al: Quantitative phosphoproteomic analysis reveals system-wide signaling pathways downstream of SDF-1/CXCR4 in breast cancer stem cells. Proc Natl Acad Sci USA 111: E2182-E2190, 2014. 